\title{
21st Century: Physical Fitness of School Age Students
}

\author{
Olga Lutkovskaya ${ }^{1}$,Elena Minenok $^{1}$, Nikolay Antipin ${ }^{1}$, Valentina Spashchanskaya ${ }^{1}$, \\ Svetlana Prokopkina ${ }^{1}$, and Anna Yushchenko ${ }^{1}$ \\ ${ }^{1}$ Department of Physical Training and Sports, Polotsk State University, Novopolotsk, Belarus
}

\begin{abstract}
Physical fitness is considered as a process of directed development of physical qualities, contributing to the formation of the necessary range of motor skills and abilities. The study of students' physical fitness was conducted by gender. Physical fitness testing was carried out according to the guidelines developed by the Ministry of Education of the Republic of Belarus. The study of physical qualities showed that the maximum increases of the indicators of physical fitness being studied do not always coincide with the rates of puberty, however, in general, the biological development of adolescents is determined by gender differences in the dynamics of physical fitness. An integral assessment of the general physical fitness of schoolchildren showed that students of all age groups, regardless gender, are at the average level of physical fitness when they are involved in sports.
\end{abstract}

\section{Introduction}

The study of the patterns of natural age-related development of physical qualities is central to the theory and methodology of physical education, because it allows us to determine biologically grounded periods of students directed improvement. The level and dynamics of the development of schoolchildren's physical qualities are largely determined by such factors as gender, age, health status, morphological and functional characteristics of the body, and the structure of physical education. At the same time, physical training of students should be based on the methodological principles of physical education, as well as on the methodological guidelines for the development of a particular physical quality and taking into account sensitive periods. Recently, a number of researchers have noted a decrease in the motor activity of school-age children, and, as a consequence, a decrease in the level of physical fitness [1-6]. In this regard, the solution to the problem of increasing the general physical fitness of students is of particular importance. Middle and senior school age is the age period when a biological predisposition to the directed development of many physical qualities remains [7].

The purpose of our research was to reveal the dynamics of physical fitness of middle and senior schoolchildren.

In accordance with the goal, the following tasks have been identified:

1. To study the current state of physical fitness in children of middle and senior school age. 
2. To determine the dynamics of physical fitness in the mode of the school curriculum for physical culture and sports.

\section{Materials and methods}

The analysis of literature data indicates that the attitude of students to systematic physical education lessons is passive $[8,9]$. In the updated school curriculum for physical education, there is a reduction in the regulatory requirements for the physical fitness of students. To increase students motivation to various forms of active physical education lessons, it is required to develop scientifically based recommendations $[10,11]$.

With a physiologically substantiated need for physical activity, special attention should be paid to the issues of motivating schoolchildren in physical education lessons, since improving the effectiveness of the educational process largely depends not only on the professionalism of the teacher, ut also on the interest of schoolchildren in active physical activity [12]. Many students perceive thematic sections related to the aspects of learning the technical and regulatory foundations of certain sports only as a necessity for obtaining positive assessments in the subject of physical education [10].

The study used general pedagogical methods: analysis and generalization of literature data, testing and methods of mathematical statistics. Specific methods used in research on theoretical and methodological problems of physical education, characterized by simplicity, reliability and high information content, are testing the level of physical fitness using control standards. During the testing, control exercises were used to assess physical fitness. Motor fitness testing was carried out using the following tests: $30 \mathrm{~m}$ running, 6 minutes running, flexibility of the spinal column, lifting the trunk from a supine position, legs fixed, hands behind the head - girls, high pull up - boys, standing long jump, shuttle run 4 × $9 \mathrm{~m}$.

The research was carried out on the basis of two schools in Novopolotsk: State Educational Institution "Lyceum", State Educational Institution "Basic School No. 10". The study involved 486 students in grades 5-11.

The data obtained during the study were mathematically processed. As a result of processing, the arithmetic mean values, the standard deviation, the error of the arithmetic mean, and the reliability of differences between the two arithmetic means were calculated. The $95 \%$ level of reliability of the results is considered sufficient. To determine the reliability of the research results, the Student's t test was used [13].

\section{Rapidity:}

1. T1 - $30 \mathrm{~m}$ running. High start, running along the stadium track. The result was determined with an accuracy of $0.1 \mathrm{~s}$.

Overall endurance:

2. T2 - running $1500 \mathrm{~m}$ (boys), $1000 \mathrm{~m}$ (girls). High start, running along the stadium track. The result was determined with an accuracy of $1 \mathrm{~s}$.

Flexibility:

3. T3 - flexibility of the spinal column. It was determined by the degree of inclination of the body forward. The subject, in the position of the pillar on the bench, bends forward to the limit without bending the knees. The flexibility of the spine is assessed using a ruler based on the distance in $\mathrm{cm}$ from the zero mark to the third finger of the hand. If the fingers do not reach the zero mark, then the measured distance is indicated by a minus (-) sign, and if below the zero mark - by a plus (+) sign.

Strength abilities:

4. T4 - sit up, legs fixed, hands behind the head (number of times) - girls. The exercise was performed on a gymnastic mat. In the initial position, the legs were bent at the knees at an angle of 90 , the arms were behind the head, the trunk was lifted until the elbows touched 
the hips. The test result was the number of lifts (times) performed in 30 seconds. One attempt was made.

High pull up (number of times) - boys. The pull-up was performed on a high bar with an overhand grip. The chin should be above the bar when pulling up. The result is evaluated by the number of times.

Speed-strength abilities:

5. T5 - standing long jump with a push of two legs. The result was determined with an accuracy of $1 \mathrm{~cm}$. The subject was asked to perform two attempts, the best result was counted.

Coordination abilities:

6. T6 - shuttle run $4 \times 9 \mathrm{~m}$. It was performed from a high start. 2 cubes were placed on the start line. The goal was to run to the finish line $(10 \mathrm{~m})$, put the cube on the line, without stopping, return for the second cube and also put it on the finish line. It was forbidden to throw the cubes. The stopwatch is turned on by the command "Go" and stopped at the moment the cube touches the floor. The result is recorded with an accuracy of $0.1 \mathrm{~s}$.

\section{Results}

The school test used to determine motor fitness at the age of 11-17 years included six tests: seated forward bend, shuttle run $4 \times 9 \mathrm{~m}$, sit up in $1 \mathrm{~min}$ (girls), high pull-up (boys), standing long jump, $1000 \mathrm{~m}$ running, $30 \mathrm{~m}$ running) [14].

Determination of physical fitness was carried out according to gender characteristics of students.

The test results are summarized in Tables 1 and 2 .

The data obtained from various tests indicate that among boys of middle and senior school age, training loads are most significantly manifested in the increase in the results of seated forward bend in grade 7 , shuttle running $4 \times 9 \mathrm{~m}$ in grade 8 , high pull-up in grade 7 , standing long jump in grade 5 , running $1500 \mathrm{~m}$ in grade 5 , running $30 \mathrm{~m}$ in grades $7-8$. This is due to the fact that the most intensive growth rate of boys occurs at the age of 13-14, when the body length increases by $7-9 \mathrm{~cm}$ per year. And in girls there is an intensive increase in growth at 11-12 years old by an average of $7 \mathrm{~cm}$. Muscle mass grows especially intensively in boys at the age of 13-14, and in girls at the age of 11-12. During puberty, the volume of the lungs between the ages of 11 and 14 almost doubles, the minute volume of respiration increases significantly and the vital capacity of the lungs (VC) increases: in boys - from $1970 \mathrm{ml}$ (12 years old) to $2600 \mathrm{ml}$ (15 years old), in girls - from $1900 \mathrm{ml}$ (12 years old) to $2500 \mathrm{ml}$ (15 years old) [15]. 
Table 1. The results of physical fitness of boys of middle and senior school age $\left(\bar{X} \pm S_{x}\right)$.

\begin{tabular}{|c|c|c|c|c|c|c|c|}
\hline Grades & $\begin{array}{c}\text { Statistic } \\
\text { al } \\
\text { Indicato } \\
\text { rs }\end{array}$ & $\begin{array}{c}\text { Seated } \\
\text { Forward } \\
\text { Bend }(\mathrm{cm})\end{array}$ & $\begin{array}{c}\text { Shuttle } \\
\text { Running } \\
4 \times 9 \mathrm{~m}(\mathrm{~s})\end{array}$ & $\begin{array}{c}\text { High Pull- } \\
\text { Up } \\
\text { (number of } \\
\text { times) }\end{array}$ & $\begin{array}{l}\text { Standing } \\
\text { Long Jump } \\
\text { (cm) }\end{array}$ & $\begin{array}{c}\text { Running } \\
1500 \mathrm{~m}(\mathrm{~s})\end{array}$ & $\begin{array}{l}\text { Running } \\
30 \mathrm{~m}(\mathrm{~s})\end{array}$ \\
\hline \multirow{2}{*}{$\begin{array}{l}\text { grades } 5 \\
(\mathrm{n}=42) \\
\text { grades } 6 \\
(\mathrm{n}=45)\end{array}$} & $\overline{\mathrm{X}} \pm \mathrm{S}_{\mathrm{x}}$ & $4.12 \pm 0.43$ & $10.99 \pm 8.53$ & $2.21 \pm 3.29$ & $1.72 \pm 2.10$ & $3.71 \pm 0.10$ & $5.73 \pm 0.12$ \\
\hline & $\overline{\bar{X}} \pm S_{x}$ & $5.51 \pm 0.57$ & $10.35 \pm 2.28$ & $5.42 \pm 0.54$ & $1.78 \pm 0.03$ & $4.49 \pm 0.11$ & $5.51 \pm 0.06$ \\
\hline \multirow{2}{*}{$\begin{array}{l}\text { grades } 6 \\
(\mathrm{n}=30) \\
\text { grades } 7 \\
(\mathrm{n}=28)\end{array}$} & $\overline{\mathrm{X}} \pm \mathrm{S}_{\mathrm{x}}$ & $5.51 \pm 0.65$ & $10.58 \pm 0.15$ & $5.07 \pm 0.72$ & $1.75 \pm 0.03$ & $4.73 \pm 0.13$ & $5.56 \pm 0.07$ \\
\hline & $\bar{X} \pm S_{x}$ & $7.04 \pm 0.69$ & $9.89 \pm 0.11$ & $7.18 \pm 0.57$ & $1.83 \pm 0.04$ & $4.44 \pm 0.16$ & $5.13 \pm 0.08$ \\
\hline \multirow{2}{*}{$\begin{array}{l}\text { grades } 7 \\
(\mathrm{n}=28) \\
\text { grades } 8 \\
(\mathrm{n}=27)\end{array}$} & $\bar{X} \pm S_{x}$ & $7.04 \pm 0.69$ & $9.89 \pm 0.11$ & $7.18 \pm 0.57$ & $1.83 \pm 0.04$ & $4.44 \pm 0.16$ & $5.13 \pm 0.08$ \\
\hline & $\bar{X} \pm S_{x}$ & $6.0 \pm 0.83$ & $9.79 \pm 0.10$ & $5.96 \pm 0.87$ & $2.05 \pm 0,04$ & $4.18 \pm 0.08$ & $5.13 \pm 0.08$ \\
\hline \multirow{2}{*}{$\begin{array}{l}\text { grades } 8 \\
(\mathrm{n}=27) \\
\text { grades } 9 \\
(\mathrm{n}=27)\end{array}$} & $\bar{X} \pm S_{x}$ & $6.0 \pm 0.83$ & $9.79 \pm 0.10$ & $5.96 \pm 0.87$ & $2.05 \pm 0.04$ & $4.18 \pm 0.08$ & $5.13 \pm 0.08$ \\
\hline & $\bar{X} \pm S_{x}$ & $10.07 \pm 0.57$ & $9.98 \pm 0.07$ & $9.52 \pm 0.42$ & $2.20 \pm 0.04$ & $5.99 \pm 0.07$ & $5.03 \pm 0.06$ \\
\hline \multirow{2}{*}{$\begin{array}{l}\text { grades } 9 \\
(\mathrm{n}=27) \\
\text { grades } 10 \\
(\mathrm{n}=25)\end{array}$} & $\overline{\mathrm{X}} \pm \mathrm{S}_{\mathrm{x}}$ & $10.07 \pm 0.57$ & $9.98 \pm 0.07$ & $9.52 \pm 0.42$ & $2.20 \pm 0.04$ & $5.99 \pm 0.07$ & $5.03 \pm 0.06$ \\
\hline & $\bar{X} \pm S_{x}$ & $7.08 \pm 1.50$ & $10.75 \pm 0.47$ & $9.4 \pm 0.86$ & $2.35 \pm 0.03$ & $5.49 \pm 0.09$ & $4.31 \pm 0.03$ \\
\hline \multirow{2}{*}{$\begin{array}{l}\text { grades } 10 \\
(\mathrm{n}=25) \\
\text { grades } 11 \\
(\mathrm{n}=25)\end{array}$} & $\overline{\mathrm{X}} \pm \mathrm{S}_{\mathrm{x}}$ & $7.08 \pm 1.50$ & $10.75 \pm 0.47$ & $9.4 \pm 0.86$ & $2.35 \pm 0.03$ & $5.49 \pm 0.09$ & $4.31 \pm 0.03$ \\
\hline & $\overline{\mathrm{X}} \pm \mathrm{S}_{\mathrm{x}}$ & $12.42 \pm 1.43$ & $9.89 \pm 0.37$ & $10.52 \pm 1.02$ & $2.26 \pm 0.06$ & $5.38 \pm 0.09$ & $4.34 \pm 0.03$ \\
\hline
\end{tabular}

Table 2. The results of physical fitness of girls of middle and senior school age $\left(\bar{X} \pm S_{x}\right)$.

\begin{tabular}{|c|c|c|c|c|c|c|c|}
\hline Grades & $\begin{array}{l}\text { Statistic } \\
\text { al } \\
\text { Indicato } \\
\text { rs }\end{array}$ & $\begin{array}{c}\text { Seated } \\
\text { Forward } \\
\text { Bend }(\mathrm{cm})\end{array}$ & $\begin{array}{c}\text { Shuttle } \\
\text { Running } \\
4 \times 9 \text { m (s) }\end{array}$ & $\begin{array}{c}\text { High Pull- } \\
\text { Up } \\
\text { (number of } \\
\text { times) }\end{array}$ & $\begin{array}{l}\text { Standing } \\
\text { Long Jump } \\
(\mathrm{cm})\end{array}$ & $\begin{array}{c}\text { Running } \\
1500 \mathrm{~m} \mathrm{(s)}\end{array}$ & $\begin{array}{l}\text { Running } \\
30 \mathrm{~m}(\mathrm{~s})\end{array}$ \\
\hline \multirow{2}{*}{$\begin{array}{l}\text { grades } 5 \\
(n=42) \\
\text { grades } 6 \\
(n=45)\end{array}$} & $\overline{\mathrm{X}} \pm \mathrm{S}_{\mathrm{x}}$ & $8.67 \pm 0.85$ & $11.10 \pm 0.17$ & $42.84 \pm 1.06$ & $1.51 \pm 0.03$ & $3.19 \pm 0.09$ & $5.88 \pm 0.07$ \\
\hline & $\overline{\mathrm{X}} \pm \mathrm{S}_{\mathrm{x}}$ & $12.65 \pm 1.0$ & $10.70 \pm 0.21$ & $46.97 \pm 0.89$ & $1.64 \pm 0.03$ & $5.22 \pm 0.17$ & $5.57 \pm 0.06$ \\
\hline \multirow{2}{*}{$\begin{array}{l}\text { grades } 6 \\
(\mathrm{n}=30) \\
\text { grades } 7 \\
(\mathrm{n}=28)\end{array}$} & $\overline{\mathrm{X}} \pm \mathrm{S}_{\mathrm{x}}$ & $12.65 \pm 1.0$ & $10.70 \pm 0.21$ & $46.97 \pm 0.89$ & $1.64 \pm 0.03$ & $5.22 \pm 0.17$ & $5.57 \pm 0.06$ \\
\hline & $\bar{X} \pm S_{x}$ & $11.67 \pm 1.22$ & $10.86 \pm 0.18$ & $47.06 \pm 1.10$ & $1.63 \pm 0.03$ & $4.80 \pm 0.09$ & $5.4 \pm 0.07$ \\
\hline \multirow{2}{*}{$\begin{array}{l}\text { grades } 7 \\
(\mathrm{n}=28) \\
\text { grades } 8 \\
(\mathrm{n}=27)\end{array}$} & $\overline{\mathrm{X}} \pm \mathrm{S}_{\mathrm{x}}$ & $11.67 \pm 1.22$ & $10.86 \pm 0.18$ & $47.06 \pm 1.10$ & $1.63 \pm 0.03$ & $4.80 \pm 0.09$ & $5.4 \pm 0.07$ \\
\hline & $\overline{\mathrm{X}} \pm \mathrm{S}_{\mathrm{x}}$ & $12.53 \pm 0.74$ & $10.62 \pm 0.11$ & $46.15 \pm 1.22$ & $1.68 \pm 0.03$ & $4.93 \pm 0.14$ & $5.52 \pm 0.07$ \\
\hline \multirow{2}{*}{$\begin{array}{l}\text { grades } 8 \\
(n=27) \\
\text { grades } 9 \\
(n=27)\end{array}$} & $\overline{\mathrm{X}} \pm \mathrm{S}_{\mathrm{x}}$ & $12.53 \pm 0.74$ & $10.62 \pm 0.11$ & $46.15 \pm 1.22$ & $1.68 \pm 0.03$ & $4.93 \pm 0.14$ & $5.52 \pm 0.07$ \\
\hline & $\bar{X} \pm S_{x}$ & $16.06 \pm 0.39$ & $10.29 \pm 0.05$ & $49.70 \pm 0.53$ & $1.81 \pm 0.02$ & $4.52 \pm 0.07$ & $5.35 \pm 0.04$ \\
\hline \multirow{2}{*}{$\begin{array}{l}\text { grades } 9 \\
(\mathrm{n}=27) \\
\text { grades } 10 \\
(\mathrm{n}=25)\end{array}$} & $\overline{\mathrm{X}} \pm \mathrm{S}_{\mathrm{x}}$ & $16.06 \pm 0.39$ & $10.29 \pm 0.05$ & $49.70 \pm 0.53$ & $1.81 \pm 0.02$ & $4.52 \pm 0.07$ & $5.35 \pm 0.04$ \\
\hline & $\overline{\mathrm{X}} \pm \mathrm{S}_{\mathrm{x}}$ & $16.0 \pm 1.23$ & $10.37 \pm 0.18$ & $51.75 \pm 1.29$ & $1.79 \pm 0.02$ & $4.70 \pm 0.08$ & $4.94 \pm 0.04$ \\
\hline \multirow{2}{*}{$\begin{array}{l}\text { grades } 10 \\
(\mathrm{n}=25) \\
\text { grades } 11 \\
(\mathrm{n}=25)\end{array}$} & $\overline{\mathrm{X}} \pm \mathrm{S}_{\mathrm{x}}$ & $16.0 \pm 1.23$ & $10.37 \pm 0.18$ & $51.75 \pm 1.29$ & $1.79 \pm 0.02$ & $4.70 \pm 0.08$ & $4.94 \pm 0.04$ \\
\hline & $\overline{\mathrm{X}} \pm \mathrm{S}_{\mathrm{x}}$ & $18.7 \pm 0.97$ & $10.02 \pm 0.15$ & $48.88 \pm 1.89$ & $1.88 \pm 0.03$ & $4.60 \pm 0.06$ & $5.10 \pm 0.03$ \\
\hline
\end{tabular}


A different picture is observed at the age of 15-17 among boys, when they surpass girls in height and body weight. Boys (on average) are 10-12 cm taller than girls and 5-8 kg heavier. The mass of their muscles in relation to the mass of the whole body is $13 \%$ more, the mass of subcutaneous adipose tissue is $10 \%$ less than that of girls. The heart of boys is $10-15 \%$ larger in volume and weight than that of girls; the pulse is less frequent by $6-8$ beats / min, the heart contractions are stronger, which leads to a greater release of blood into the vessels and a higher blood pressure. Girls breathe more often and not as deeply as young men; the vital capacity of their lungs is approximately $100 \mathrm{~cm}^{3}$ less [16].

The result of Seated Forward Bend test allows us to state that in boys from 11 to 15 years old, there is generally a progressive development of flexibility with the highest growth rates from 14 to 15 years ( $p>0.05)$ and with a slight decrease from 13 to 14 years. The results obtained are consistent with the established age dynamics of the natural development of flexibility in boys and young men of middle and senior school age [11]. A distinctive feature of the identified indicators of flexibility is a high test result among young men at the age of 17 (see Table 1, Fig. 1).

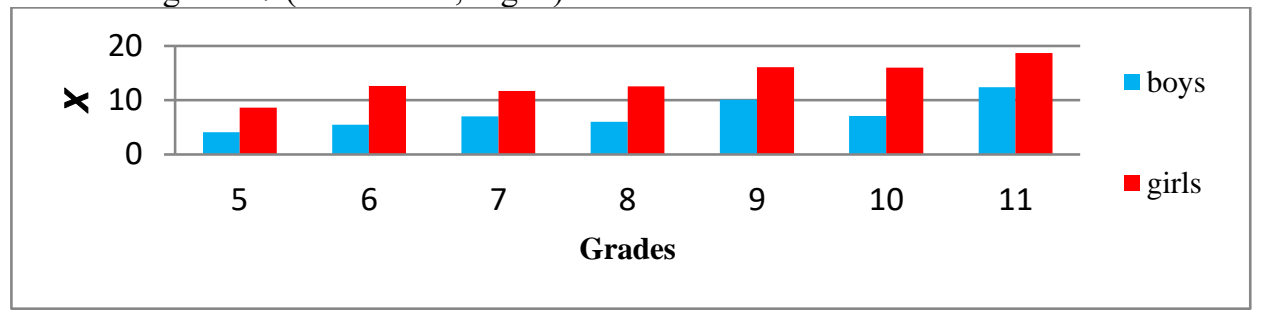

Fig. 1. Dynamics of changes in flexibility $(\mathrm{cm})$.

A slightly different dynamics of the development of flexibility is observed in girls from 11 to 17 years old. From 11 to 12 years old, a significant increase in the studied indicator was recorded ( $p>0.05$ ), from 12 to 14 years old, the indicators as a whole stabilize with minor fluctuations in decrease and increase. At the same time, according to T.Y. Krutsevich (2003) the age period from 12 to 14 years old in girls is characterized by high rates of increase in flexibility. As well as in boys, there is a high increase in the flexibility index in the test among girls at the age of 17 (see Table 2, Fig. 2).

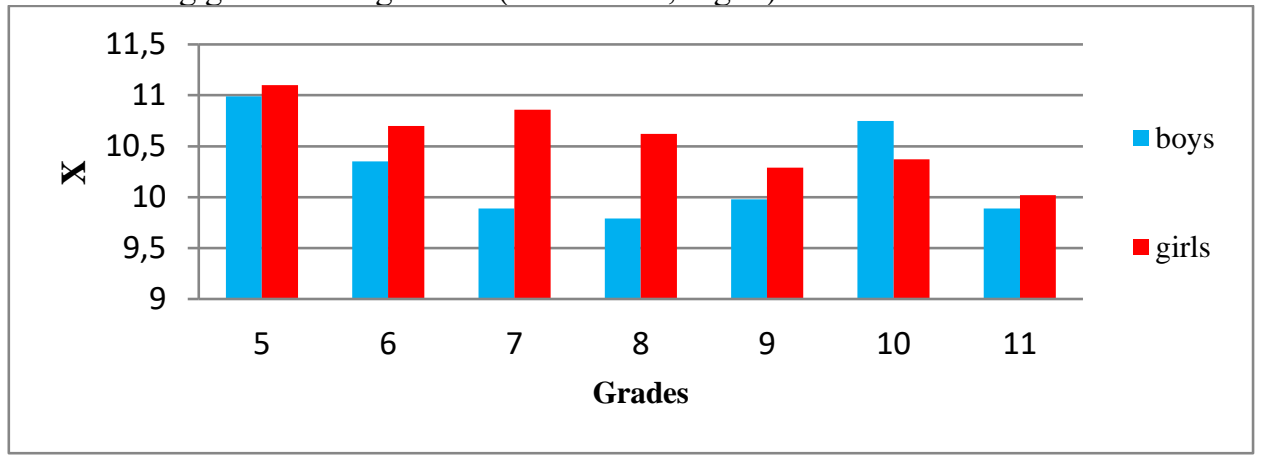

Fig. 2. Dynamics of changes in coordination abilities (s).

Coordination abilities at school age are determined by the results of Shuttle Run $4 \times 9 \mathrm{~m}, \mathrm{~s}$ Test . Testing of boys showed that from 11 to 14 years old there is a significant and stable decrease in coordination abilities (see Table 1, Fig. 2), but from 15 to 16 years old, there is an increase ( $p>0.05)$ with a subsequent sharp decrease at the age of 17 . The 
revealed dynamics of the development of coordination abilities of boys in grades 5-11 in general does not agree with the established age dynamics of the natural development of coordination abilities in boys and young men of middle and senior school age [17]. According to L. Volkov, the age period from 11 to 12 years is characterized by high rates of biological development of this ability, from 13 to 14 years old, the growth rates are average. Studies have shown that in girls the greatest increase in coordination abilities is observed at the age of 11 , and from 13 to 17 years old, there is a wave-like decrease in the indicator of coordination abilities. (see Table 2, Fig. 2). The obtained results generally do not contradict the revealed tendency of age-related development of coordinating abilities in the studies of L. Volkov, 2001 [17]. Thus, it can be assumed that in the case under study, the content of physical culture lessons was only to an insignificant extent aimed at the development of students' coordination abilities, and also to conclude that coordination abilities can be improved throughout the school age. The development of strength abilities was determined by the results of two tests "Sit Up in $1 \mathrm{~min}$ " (number of times for girls) and "High Pull-Up" (number of times for boys). The study made it possible to establish that the indicators of strength abilities for boys and girls from 11 to 14 years old are characterized by uniform development ( $>>0.05$ ), and from the age of 15 , there is a progression of a high growth rate $(\mathrm{p}<0.05)$, where this indicator remains stable up to the age of 17 (see Tables 1 , 2, Fig. 3).

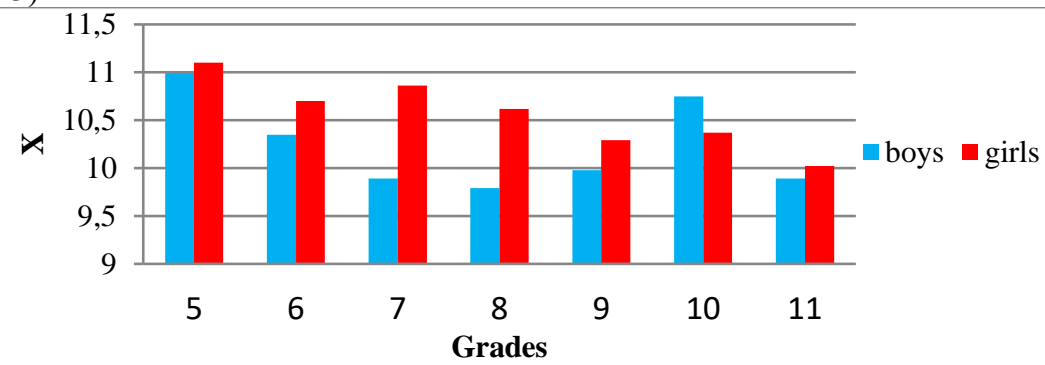

Fig. 3. Indicators of strength abilities, times.

The data obtained allow us to conclude that the stabilization of these indicators in girls (from 12 years old) and boys (from 15 years old) occurs due to insufficient motor loads aimed at developing the flexor muscles of the trunk. Taking into account the particular importance of the development of the muscular corset in the formation of posture and for the physiological development of internal organs, the content of physical activity (exercises) should stimulate the development of these muscle ensembles.

The results of determining muscle power correlate well with jumping testing [18], anaerobic or aerobic potential [1], and the composition of muscle fibers of various types [2]. Various jumps, including standing long jumps, are very popular among young people. Features of age-related development of speed-strength qualities according to our data are presented in Table 1.

The result of performing Standing Long Jump Test allows us to compare the data on the age-related development of speed-strength qualities in boys from 11 to 16 years old and indicate an obvious increase in these indicators (see Table 1, Fig. 4). The most significant increases in these qualities for boys were determined from 14 to 16 years old ( $p>0.05)$, while at 17 years old there was already a slight decrease in this indicator.

The data obtained in the study of girls from 11 to 17 years old made it possible to record an increase in this indicator $(\mathrm{p}>0.05)$. The most significant increases were noted at the age of 15-17 years (Fig. 4). 
It is believed that the results of Standing Long Jump can be used to judge the speedstrength abilities and the contractile ability of muscles [18]. Standing Long Jump indicators to a certain extent point out the level of muscle power and, to a certain extent, the predisposition to the manifestation of coordination abilities. Based on the above, it is important to determine the age periods of the greatest increases in speed-strength qualities, which are based on oxygen-free mechanisms of muscle activity [1].

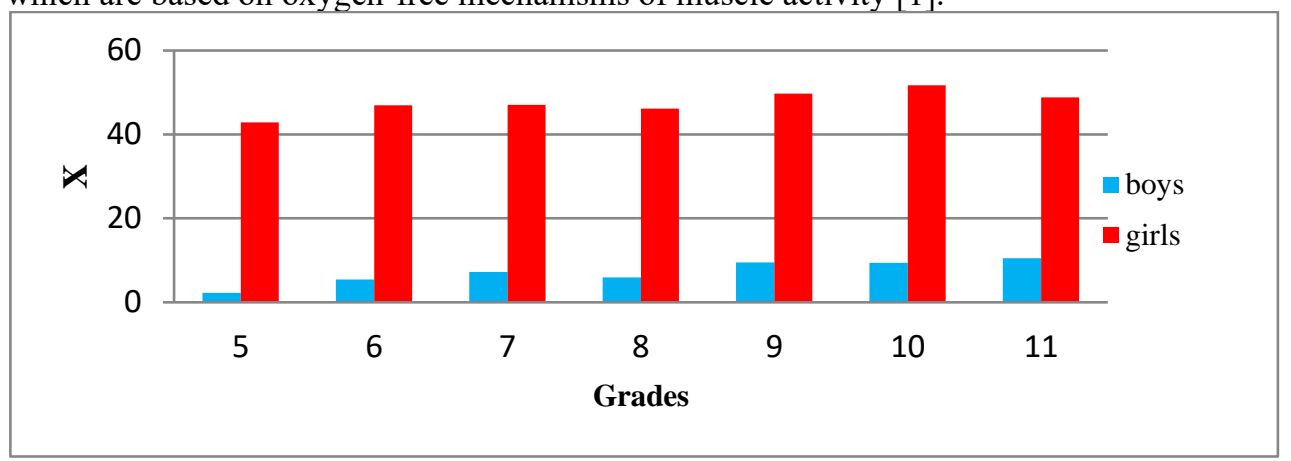

Fig. 4. Indicators of the development of speed- strength qualities, $\mathrm{cm}$.

The overall endurance of the subjects was determined using Running $1500 \mathrm{~m}$ Test (boys) and Running $1000 \mathrm{~m}$ Test (girls). The result of Running $1500 \mathrm{~m}$ Test made it possible to state that boys from 11 to 12 years old and from 14 to 15 years old ( $p>0.05$ ) have high rates of increase in overall endurance and with a slight decrease from 13 to 14 years old. However, from 16 to 17 years old, the indicators generally stabilize with minor fluctuations in decline. The results obtained are consistent with the established age dynamics of the natural development of overall endurance in boys and young men of middle and senior school age. A distinctive feature of the revealed indicators of overall endurance is a high test result among 15-year-old boys (see Table 1, Fig. 5).

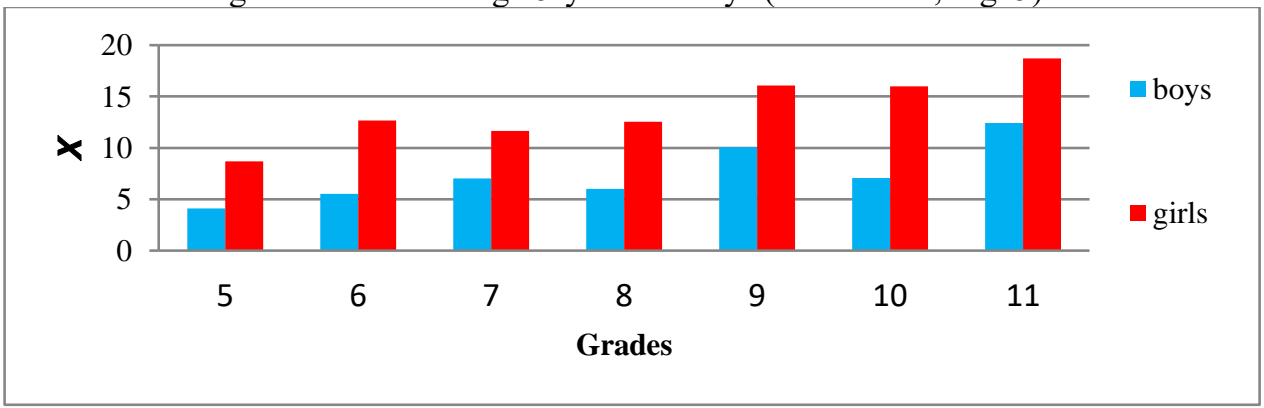

Fig. 5. Results of testing general endurance, s.

We believe that by the age of 15-16, the oxygen type of bioenergy is mainly formed. According to some researchers [3], it is indicated that the most optimal age in the development of this physical quality is the period of 11-14 years. It should be noted that the basis of the predisposition to the development of various physical qualities is formed by the regularities of the formation of the bioenergetic systems of the body and therefore it is very difficult to substantiate the expediency of preferential development, for example, of speed qualities, and then of overall endurance. Therefore, the statement that the period of the greatest growth of any of the analyzed physical qualities determines the presumptive accentuated direction of its development requires additional confirmation. 
The data on the growth of the analyzed endurance trait in girls from 12 to 17 years old are represented by a smoother hage of $12(\mathrm{p}<0.05)$. The average rate of its growth falls on the age from 15 to 17 . The results obtained are consistent with the established age dynamics of the natural development of overall endurance in girls of middle and senior school age. [11].

According to the results of endurance testing, we can conclude that test loads (running at a distance of $1000 \mathrm{~m}$ and $1500 \mathrm{~m}$ ) do not sufficiently motivate students to reveal their aerobic potential. According to the data obtained, for the development of general endurance for girls, the most justified age is 12-13 years old, for boys - 15-17 years old.

The results of the study of Running $30 \mathrm{~m}$ Test show that boys from 11 to 17 years old gradually deteriorate the rate of speed (see Table 1, Fig. 6). In the 11-year period, there is an improvement in this indicator in relation to the 12- and 13-year-olds $(\mathrm{p}>0.05)$. At the age of 14 , there is also an improvement in relation to the 15 - and 16-year-olds ( $>0.05)$ (Fig. 6).

In speed development among girls, there are two types of decline from 11 to 12 years old, and uniform increases from 13 to 15 years old. In our studies, increases in these qualities are noted up to the age of 12 , then at the age of 15-17, a decrease in its indicators is observed.

The greatest growth in results is at the age of 11-15. When analyzing age-related increases in speed capabilities, it can be noted that their most pronounced improvements for boys are noted at the age of 12 , and then there is a significant decrease in the growth of this function (Fig.6).

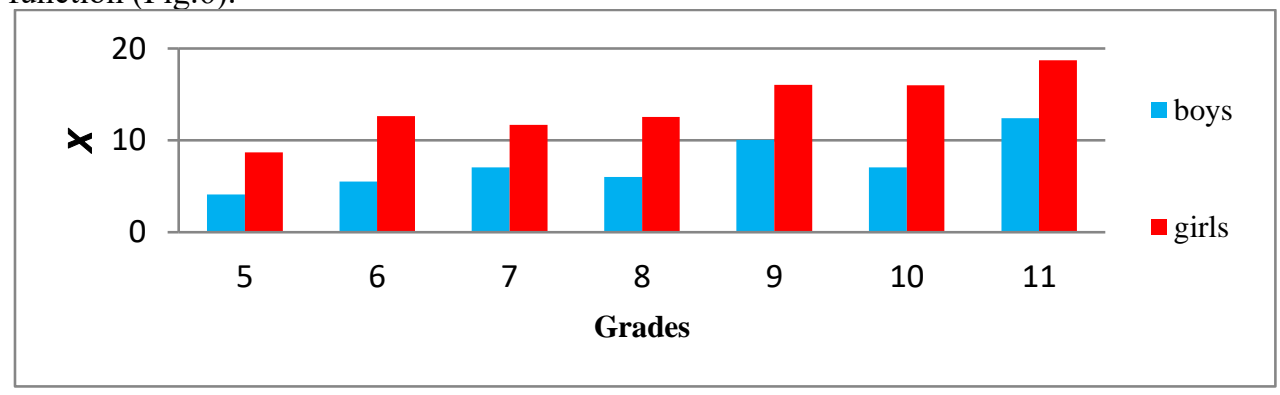

Fig. 6. Speed test results, s.

It is believed that the rate of muscle contraction is determined by the activity of enzymes involved in the activation of anoxic bioenergetic processes, as well as by the number of muscle fibers of rapid contraction [19, 20].

An external indicator of the potential of anoxic bioenergetic processes is the dynamics of the speed function develoment. The data obtained may indicate some delay in the development of this quality. The speed qualities development of girls occurs with a certain temporal advance in relation to boys. We believe that the dynamics of the speed qualities development may indicate the peculiarities of the formation of anoxic sources of bioenergy.

\section{Conclusion}

The data of the study of the physical fitness of schoolchildren in ontogenesis indicate that the maximum increases in the studied indicators of physical fitness do not always coincide with the rates of puberty, however, in general, biological development of adolescents is determined by gender differences in the dynamics of physical development. Therefore, girls are characterized by an earlier accelerated development of somatic indicators, and boys are 
characterized by a later and longer period of accelerated physical development. Adolescents of the same age, but with different degrees of biological maturation, have significant differences in body length and weight, and the dynamics of age-related changes in these features has its own peculiarities in boys and girls. An integrated assessment of the general physical fitness of schoolchildren showed that students of all age groups, regardless of gender and involvement in sports, are at the average level of physical fitness.

It has been established that the development of physical qualities of schoolchildren in the age period from 11 to 17 is heterochronous and heterodynamic. In the age-related development of each of the studied physical qualities, there are several periods of pronounced growth (from two to four). The characteristics of the level of traditional health indicators and, notably, indicators of physical fitness are directly related to physical health. Physical health, as known, is liable to pedagogical influence. Thus it is possible to control physical health level, physical and mental performance, mental productivity, success in vocational training.

\section{References}

1. Bernshtein, N.A. Essays on the physiology of movement and the physiology of activity (Moscow: Medicine, 1966)

2. Vysotskiy, A.I. Peculiarities of developing the need for physical exercises in schoolchildren (Physical Education, 1996)

3. Aider, E. Development and directed improvement of physical qualities in schoolchildren (Shchetsin, 2000)

4. Polnevskiy, I. Physical education of students (Medicine, 1999)

5. Baranov, A.A. Physical development of children and adolescents at the turn of the millennium (Children's Health Scientific Centre, Russian Academy of Medical Sciences, -2008.)

6. Godik, M.A. Physical training (Olimpia, 2006)

7. Markelov, A.G. Needs and interests of young people as basic factors in managing the development of physical culture at the city (municipal) level: Cand. ped. sci. diss.

( Moscow, 2000)

8. Stolyarov, V. I. Sociology of physical culture and sports (Phys. culture, 2004)

9. Bezverhnyaya, G.V. Age dynamics of schoolchildren's motivational priorities for physical culture and sports, Kharkov: XXIII, 22 (2000)

10. Filin, V.P. Youth sports fundamentals (Physical culture and sports, 2001)

11. Krutsevich, T.Y. Theory and methodology of physical education. 2nd vol. (Olymp. lit., 2003)

12. Romanenko, N. I., Haimova, Y. I. Increasing motivation for types of physical activity, of the scientific conference of students and young scientists of universities of the Southern Federal District, Krasnodar, KGUFKST (2008)

13. Godik, M.A. Sports metrology (Physical culture and sports, 1988)

14. Instructional and methodological letter of the Ministry of Education of the Republic of Belarus "On the organization in 2020/2021 academic year of the educational process in the study of academic subjects and the conduct of optional classes to implementn in educational programmes of general secondary education": "Educational process peculiarities in teaching Physical Education"

15. Fomin N.A. Age foundations of physical education (Physical culture and sports, 2002) 
16. Abzalov, R. A. Regulation of the functions of the heart of an immature organism under various motor modes (Kazan, 1987)

17. Volkov, L.V. Physical abilities of children and adolescents (Health, 1981)

18. Tumanyan, G.S. Flexibility as a physical quality, Theory and practice of physical culture, 2 (2002)

19. Samsonova, A.V. Muscle biomechanics: an educational guide (St.Petersburg, 2008)

20. Kholodov, J.K. Theory and methodology of physical education in sports: textbook for university students (Academy, 2003). 